\title{
Influence of physicochemical properties of gasoline on the formation of DISI engine fuel injector deposits
}

This paper describes the results of an engine study of the tendency for fuel injector deposits to form by gasolines of various compositions. Since the factors promoting the formation of fuel injector deposits in DISI engines have, in many cases, been insufficiently identified they require further research and investigation work, which was the greatest motivation for undertaking this project. The latest CEC F-113-KC test procedure for the most damaging deposits in DISI engine injectors was used for this purpose. The research results obtained in the framework of the conducted project indicated T90, aromatic and olefinic hydrocarbons, sulphur, ethanol, DVPE, IBP and fuel density as the most important factors causing the increase in the tendency for deposits to form on the injectors of SI type DISI engines.

Key words: direct injection spark ignition engine, injector deposits, deposit control additives, fuel, engine tests

\section{Introduction}

The problem of formation of harmful deposits on various elements of gasoline and diesel engines has been known for about 50 years. The need to prevent the formation of these deposits has forced the gradual development and implementation of various engine testing and evaluation methods as well the effectiveness of various solutions to reduce deposits formation. This is reflected in subsequent editions of the World-Wide Fuel Charter, where successively verified procedures of testing harmful engine deposits are indicated, adjusted to the requirements of changing fuel formulations, their categories and successive generations of engines. For testing deposits formed in SI engines, the World-Wide Fuels Charter (2013 edition) indicates the following American methods: ASTM D 5500, ASTM D 6201, ASTM D 5598, and ASTM D 6241 and European methods: CEC F-05-93 (M102E), CEC F-16-96 (VW Boxer), and CEC F-20-98 (M111) [1]. All the American methods assume testing in cars or engines dating back to the 1980 s, with only indirect fuel injection engines. The tests include evaluation of deposits on intake valves and in fuel injectors. European methods assume that all of the above tests are conducted on port fuel injection (PFI) indirect fuel injection engines dating back to the 1990s. The evaluations concern deposits on intake valves and in combustion chambers. Therefore none of the mentioned methods are representative for the currently most widespread both in the USA and in Europe direct injection SI engines (direct injection spark ignition DISI/gasoline direct injection GDI).

The direct injection technology has allowed engine manufacturers to meet the emission and fuel consumption (engine efficiency improvement) targets imposed by progressively more stringent regulations. However, it changed the need for testing and evaluation of harmful deposits. It turned out that in this type of engines, the deposits that have the most harmful effect on the correct and reliable functioning of the engine are the fuel injector deposits. The influence of contaminated fuel injectors on the deterioration of the engine operating characteristics, its emissions and performance has been studied and described in many works [2-11]. Gradually increasing injector deposits enforce the need for constant, precise verification and tuning of the amount of fuel injected into the engine combustion chamber - Fig. 1.

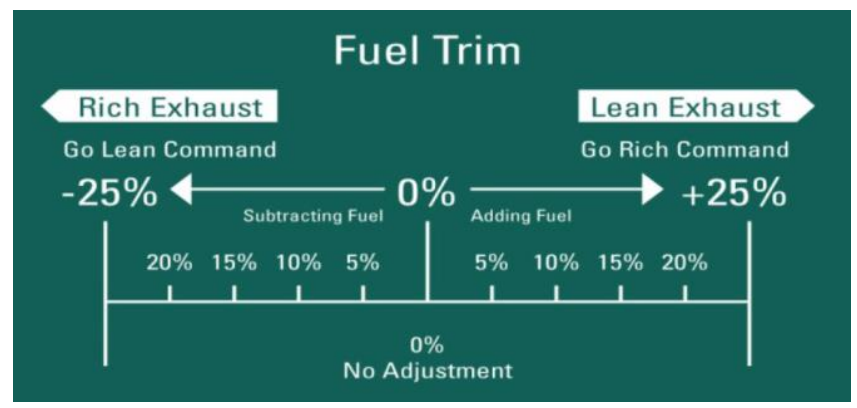

Fig. 1. Tuning the size of the fuel dose to the needs of the combustible mixture formed with an excess air ratio of $\lambda=1$ [12]

This is necessary in order to maintain the constant excess air ratio of $\lambda=1$ required for the correct and reliable operation of the commonly used three-way exhaust catalytic converters. For this purpose, a lambda sensor installed in the engine exhaust system constantly monitors the oxygen content of the exhaust gases. This information is transmitted to the engine's control unit (ECU), which simultaneously receives information from an air mass sensor that monitors the mass flow rate of the air supplied to the engine. On this basis the amount of fuel that should be delivered to the combustion chamber under specific engine operating conditions is calculated. This in turn is the basis for controlling the width of the electrical impulse which determines the length of the fuel injection time, varying depending on the operating conditions of the engine, but also on the degree of contamination of the injectors. Therefore, the on-board computer must immediately make corrections to the dosed fuel when changes in the excess air ratio indicate a mixture that is too lean or too rich.

These adjustments are made on average several times per second and are referred to as short term fuel trim (STFT) adjustments. The continuous change of the short term fuel trim correction is communicated to the engine's on-board computer to determine the long term fuel trim (LTFT) correction which is significantly affected by the 
injector deposits formed. As injector deposits increase, the engine's on-board computer gradually increases the fuel dose injection time to compensate for the decreasing fuel flow rate out of the injectors. However, when the amount of long term fuel trim correction exceeds $25 \%$, fuel injection system dysfunction occurs and the engine stops [12].

It is anticipated that compliance with future, even stricter regulations for reducing emissions of harmful components of exhaust gases will be possible by further optimization of the processes of preparation and combustion of the combustible mixture in the engine cylinders. This will require further increasing the fuel injection pressure, reducing the diameter of fuel outlet channels in injectors and increasing their precision. As a result, counteracting the formation of injector deposits becomes even more important, as the injectors will be even more sensitive to fouling with deposits disrupting their functioning. Therefore, fuel properties and especially effectiveness of deposit control additives DCA type packages will play a decisive role in maintaining by the engine, during its lifetime, parameters and performance declared by its manufacturer. Unfortunately, DCA type additives are not always equally effective for direct and indirect injection engines. Meanwhile, both European and U.S. recognized test procedures for sediment testing and evaluation have been developed based on PFI indirect fuel injection SI engines. The results of these tests do not allow extrapolation and evaluation of the performance of DCA type additives for DISI engines. This has led to the development by automotive as well as fuel additive manufacturing companies of at least several different engine "inhouse" methods to evaluate the performance of DCA-type additives [13, 14]. However, the results of evaluations carried out by these methods are incomparable due to different test conditions. The experience gained and observations made in this way allowed to determine the most important guidelines to be followed in the development of an effective, generally applicable test allowing for quick generation of the tested deposits and reliable fuel assessment as regards the tendency to keep clean the injectors of DISI SI engines and the ability to wash out the deposits after their earlier generation. These indications are detailed below [5, 15-17]:

- the most favourable operating conditions for deposit formation in a DISI engine are steady state operation at mid revs (typically 1500-2500 rpm) and medium to low load,

- temperature to which the injector tip gets heated plays a crucial role in the formation of deposits on the injectors (when T90 is higher than the injector tip temperature the propensity for deposits to form will be greater),

- apart from DCA, the rate and amount of deposit formation in the injectors is also influenced by the fuel composition (e.g. the higher the content of olefinic hydrocarbons and sulphur in the fuel, the greater the deposit formation tendency),

- the lower the injected fuel pressure, the higher the susceptibility to deposits,

- the operation of the engine under steady-state conditions keeps the temperature of the injector tips stable, i.e. it is always below or above the T90 temperature of the fuel,
- sufficient time to carry out "Clean-Up" type tests, guaranteeing repeatability of results is usually between 25 and 50 hours.

In 2016, the CEC formed a new TDG-F-113 DISI Working Group and began developing a test procedure that meets the above expectations.

In an effort to reduce the cost and time of developing the test procedure, an existing test method developed "Inhouse" by VW was adopted as its basis. The first "Draft" of the procedure was released in December 2017. The procedure was designated CEC F-113-KC and named VW EA111 DISI Injector Deposit Test. The VW EA111 BLG engine, widely known and used in many VW families, was used as the test tool.

It is a DISI engine, with combined supercharging system (mechanical supercharging + turbocharging) built in the "downsizing" convention. The basic parameters of the engine are shown in Table 1. The engine is equipped with wall-guided category fuel injection. For fuel injection 6-hole injectors controlled electromagnetically were used.

Table 1. Basic technical parameters of VW EA111 BLG engine

\begin{tabular}{|l|l|}
\hline Engine Code & BLG-EA111 \\
\hline Type & 4 -cylinder in-line engine \\
\hline Displacement & $1390 \mathrm{~cm}^{3}$ \\
\hline Bore & $76,5 \mathrm{~mm}$ \\
\hline Stroke & $75,6 \mathrm{~mm}$ \\
\hline Valves per Cylinder & 4 \\
\hline Compression Ratio & $10: 1$ \\
\hline Maximum Output & $125 \mathrm{~kW}$ at $6000 \mathrm{rpm}$ \\
\hline Maximum Torque & $220 \mathrm{Nm}$ at $1750-4500 \mathrm{rpm}$ \\
\hline Engine Management & Bosch Engine Management \\
\hline Fuel & $\begin{array}{l}\text { Super Plus at RON } 98 \text { (Super unleaded at RON 95 with slightly } \\
\text { higher consumption and torque reduction in the low rev ranges) }\end{array}$ \\
\hline Exhaust Gas Treatment & Main catalytic converter. Lambda control \\
\hline Emission Standard & EU4 4 \\
\hline
\end{tabular}

The current version of the CEC F-113-KC procedure (November 2020) allows the evaluation of fuels (DCA additives) to be conducted according to two tests, as follows:

1) "Keep-Clean" Test

This is a 48 hour test during which the engine works under constant speed (2000 rpm) and constant load (56 $\mathrm{Nm}$ ). It allows to evaluate the base or upgraded fuel in terms of its ability to keep the injectors clean.

2) "Dirty-Up \& Clean-Up" Test

Consists of a $48 \mathrm{~h}$ part of the "Dirty-Up" test performed according to the "Keep-Clean" test and a $24 \mathrm{~h}$ part of the "Clean-Up" test in which the engine operates under the same conditions as in "Dirty-Up" or "Keep-Clean". The test allows to evaluate cleaning properties of the fuel used in the "Clean-Up" part of the test.

The pressure of the fuel injected during the test is 77 bar.

The criterion of evaluating the tendency of the fuel to form deposits on the injectors in the conducted test is the changing width of the electric impulse controlling the time of injection of the fuel dose. This time changes (lengthens) as the amount of deposits accumulating outside and inside the injector gradually increases. Figure 2 shows the results of typical runs of "Keep-Up" and "Dirty-Up \& Clean-Up" tests carried out according to the CEC F-113-KC procedure [18, 19]. 


\section{Research aim}

The aim of this study was to analyze the influence of gasoline composition and its various physicochemical properties on the tendency to form deposits on the injectors of DISI engine based on tests carried out in accordance with the procedure CEC F-113-KC (VW EA111 BLG).

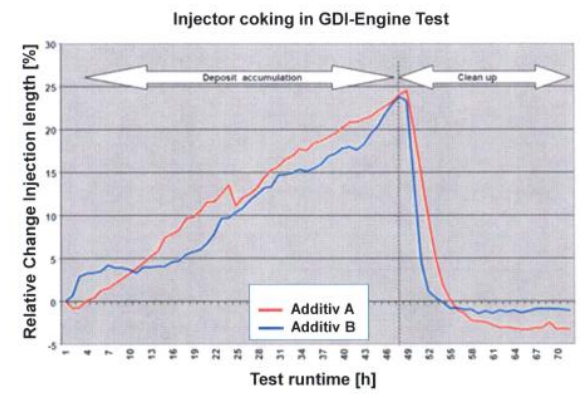

Fig. 2. Typical run of "Keep-Clean" and "Dirty-Up" \& Clean-Up" tests (one fuel and two different DCA additives) [19]

\section{Test method}

Tests on prepared petrol samples were carried out according to test procedure CEC F-113-KC with use of test engine VW EA111 BLG at the Oil and Gas Institute - National Research Institute - Fig. 3. All tests were carried out on the same set of injectors washed after each test.

\section{Materials}

Seven petrols differing in physicochemical properties and amount of alcohol (ethanol) contained in them were tested in engine tests. While selecting the gasolines, the need of estimating the influence of their different physicochemical parameters and contained alcohol on the tendency to form deposits in the injectors of VW EA111 BLG engine was taken into account. In order to better distinguish the influence of different physicochemical properties on the tendency to deposit formation, fuels not containing DCA type additive packages were used for testing. The physicochemical properties of the prepared fuel samples for engine testing are presented in Table 2.

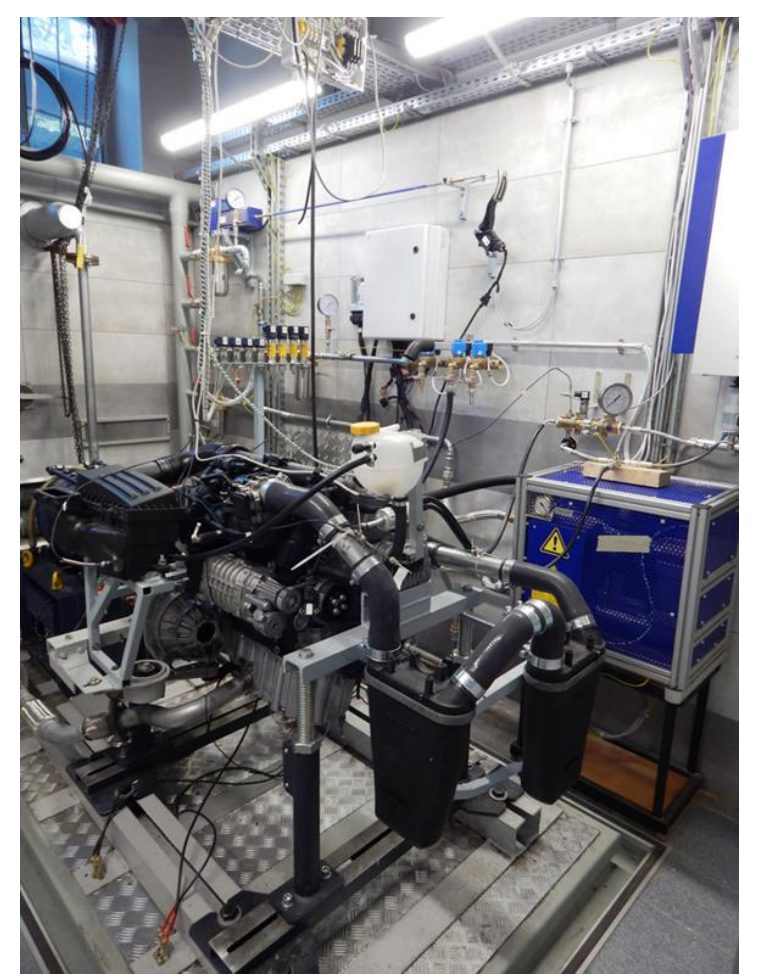

Fig. 3. General view of engine test bed with VW EA111 BLG engine

Table 2. Physicochemical properties of gasoline samples prepared for engine testing

\begin{tabular}{|c|c|c|c|c|c|c|c|c|c|}
\hline \multirow[t]{2}{*}{ Properties } & \multirow[t]{2}{*}{ Units } & BB $95-1$ & BB $95-2$ & BB $95-3$ & BB $98-1$ & BB $98-2$ & $\begin{array}{c}\text { BB } 95-3 \\
+10 \%(V / V) \\
\text { ethanol }\end{array}$ & $\begin{array}{c}\text { BB } 98-1 \\
+10 \%(V / V) \\
\text { ethanol }\end{array}$ & \multirow[t]{2}{*}{ Test method } \\
\hline & & 1 & 2 & 3 & 4 & 5 & 6 & 7 & \\
\hline Density at temperature $15^{\circ} \mathrm{C}$ & $\mathrm{kg} / \mathrm{m}^{3}$ & $762,3 \pm 0,4$ & $751,2 \pm 0,4$ & $739,3 \pm 0.4$ & $742,5 \pm 0,4$ & $725,6 \pm 0,4$ & $744,1 \pm 0,4$ & $748,4 \pm 0,4$ & PN-EN ISO $12185: 2002^{A}$ \\
\hline Research Octane Number (LOB) & - & 95,7 & 97,6 & 95,3 & 98,8 & 98,8 & 96,8 & 101,0 & PN-EN ISO $5164^{A}$ \\
\hline Motor Octane Number (LOM) & - & 85,1 & 86,0 & 85,5 & 87,2 & 89,6 & 86,7 & 88,7 & PN-EN ISO $5163^{A}$ \\
\hline Sulphur & $\mathrm{mg} / \mathrm{kg}$ & $45,6 \pm 6,4$ & $4,5 \pm 1,2$ & $7,6 \pm 1,6$ & $6,8 \pm 1,5$ & $2,8 \pm 1,0$ & $6,5 \pm 1,5$ & $6,5 \pm 1,5$ & PN-EN ISO 20846:2020 \\
\hline Induction period & minuty & $>360$ & $>360$ & $>360$ & $>360$ & $>1200$ & $>360$ & $>360$ & PN-EN ISO $7536.2011^{\mathrm{A}}$ \\
\hline Washed gums & $\mathrm{mg} / 100 \mathrm{ml}$ & $3,0 \pm 2,5$ & $2,5 \pm 2,3$ & $2,5 \pm 2,3$ & $1,5 \pm 2,0$ & $\mathbf{1 , 0} \pm 1,5$ & $1,0 \pm 1,5$ & $1,0 \pm 1,5$ & PN-EN ISO 6246:2017-05 \\
\hline $\begin{array}{l}\text { Hydrocarbon content of type: } \\
\text {-olefin } \\
\text {-aromatic }\end{array}$ & $\begin{array}{l}\%(V N) \\
\%(V N)\end{array}$ & $\begin{array}{c}9,8 \pm 1,4 \\
\mathbf{4 0}, \mathbf{6} \pm 2,8\end{array}$ & $\begin{array}{l}8,5 \pm 2,1 \\
32,8 \pm 2,6\end{array}$ & $\begin{array}{r}\mathbf{9 , 2} \pm 2,2 \\
\mathbf{2 6 , 2} \pm 2,6\end{array}$ & $\begin{array}{l}4,0 \pm 1,1 \\
30,7 \pm 2,6\end{array}$ & $\begin{array}{r}\mathbf{4}, \mathbf{4} \pm 1,1 \\
20,8 \pm 2,6 \\
\end{array}$ & $\begin{array}{r}9,1 \pm 2,2 \\
23,7 \pm 2,6\end{array}$ & $\begin{array}{c}\mathbf{4}, \mathbf{0} \pm 1,1 \\
\mathbf{2 6 , 5} \pm 2,6\end{array}$ & PN-EN $15553: 2009^{\wedge}$ \\
\hline Benzene & $\%(V N)$ & $0,4 \pm 0,1$ & $0,7 \pm 0,1$ & $0,5 \pm 0,1$ & $0,5 \pm 0,1$ & $0,3 \pm 0,1$ & $0,5 \pm 0,1$ & $0,4 \pm 0,1$ & $\begin{array}{l}\text { PN-EN 238:2000 } \\
+ \text { +A1:2008 }\end{array}$ \\
\hline Oxygen & $\%(m / m)$ & $<0,01$ & $1,81 \pm 0,21$ & 0,77 & $1,96 \pm 0,21$ & $<0,01$ & $4,6 \pm 0,47$ & $5,5 \pm 0,51$ & PN-EN $1601: 2017-09^{A}$ \\
\hline \multicolumn{10}{|l|}{ Oxygen-containing organic compound content: } \\
\hline -methanol & $\%(V N)$ & $<0,17$ & $<0,17$ & $<0,17$ & $<0,17$ & $<0,17$ & $<0,17$ & $<0,17$ & \multirow[t]{7}{*}{ PN-EN 1601:2009^ } \\
\hline -ethanoll & $\%(V N)$ & $<0,17$ & $<0,17$ & $<0,17$ & $0,2 \pm 0,07$ & $<0,17$ & $10,4 \pm 0,57$ & $10,6 \pm 0,57$ & \\
\hline - isopropyl alcohol & $\%(V N)$ & $<0,17$ & $<0,17$ & $<0,17$ & $<0,17$ & $<0,17$ & $<0,17$ & $<0,17$ & \\
\hline - tert-butyl alcohol & $\%(V M)$ & $<0,17$ & $<0,17$ & $<0,17$ & $<0,17$ & $<0,17$ & $<0,17$ & $<0,17$ & \\
\hline - isobutyl alcohol & $\%(V N)$ & $<0,17$ & $<0,17$ & $<0,17$ & $<0,17$ & $<0,17$ & $<0,17$ & $<0,17$ & \\
\hline - ethers (with 5 or more carbon atoms) & $\%(V N)$ & $<0,17$ & $10,1 \pm 0,57$ & $4,8 \pm 0,28$ & $12,1 \pm 0,64$ & $10,2 \pm 0,57$ & $4,9 \pm 0,28$ & $10,4 \pm 0,57$ & \\
\hline - other organic compounds containing oxygen & $\%(V M)$ & $<0,17$ & $<0,17$ & $<0,17$ & $<0,17$ & $<0,17$ & $<0,17$ & $<0,17$ & \\
\hline Vapour pressure (DVPE) & $\mathrm{kPa}$ & $54,2 \pm 1,1$ & $\mathbf{7 4 , 2} \pm 1,1$ & $\mathbf{5 8 , 9} \pm 1,1$ & $69,2 \pm 1,1$ & $\mathbf{5 7 , 8} \pm 1,1$ & $65,0 \pm 1,1$ & $73,2 \pm 1,1$ & PN-EN $13016-1.2018-05^{A}$ \\
\hline $\begin{array}{l}\text { Fractional composition: } \\
\text {-IBP } \\
\text { - end of distillation temperature } \\
\text { - distils } \\
\text { - residue } \\
\text { - losses } \\
\text { - evaporation temperature } 10 \%, \text { T10 } \\
\text { - evaporation temperature } 50 \%, T 50 \\
\text { - evaporation temperature } 90 \%, \text { T90 }\end{array}$ & $\begin{array}{l}{ }^{\circ} \mathrm{C} \\
{ }^{\circ} \mathrm{C} \\
\%(V N) \\
\%(V N) \\
\%(V N) \\
{ }^{\circ} \mathrm{C} \\
{ }^{\circ} \mathrm{C} \\
{ }^{\circ} \mathrm{C}\end{array}$ & $\begin{array}{c}37,4 \pm 3,4 \\
214,9 \pm 5,1 \\
97,3 \\
1,0 \\
1,7 \\
52,3 \pm 2,6 \\
106,5 \pm 3,6 \\
172,9 \pm 4,0\end{array}$ & $\begin{array}{c}34,8 \pm 3,4 \\
196,5 \pm 5,1 \\
97,1 \\
1,2 \\
1,7 \\
48,8 \pm 2,6 \\
93,4 \pm 3,1 \\
156,5 \pm 4,0\end{array}$ & $\begin{array}{c}37,5 \pm 3,4 \\
196,9 \pm 5,1 \\
97,5 \\
1,2 \\
1,3 \\
51,9 \pm 2,6 \\
88,3 \pm 2,9 \\
157,8 \pm 4,1\end{array}$ & $\begin{array}{c}33,6 \pm 4,8 \\
185,0 \pm 5,1 \\
97,6 \\
1,0 \\
1,4 \\
48,8 \pm 2,6 \\
88,2 \pm 2,9 \\
148,4 \pm 4,0\end{array}$ & $\begin{array}{c}42,1 \pm 3,4 \\
185,1 \pm 5,1 \\
97,9 \\
1,0 \\
1,1 \\
67,3 \pm 2,6 \\
101,8 \pm 3,5 \\
144,9 \pm 4,1\end{array}$ & $\begin{array}{c}38,6 \pm 3,4 \\
194,2 \pm 5,1 \\
97,5 \\
1,0 \\
1,5 \\
49,3 \pm 2,6 \\
67,4 \pm 3,6 \\
153,4 \pm 4,0\end{array}$ & $\begin{array}{c}28,3 \pm 3,4 \\
183,9 \pm 5,1 \\
97,5 \\
1,0 \\
1,5 \\
47,8 \pm 2,6 \\
70,6 \pm 2,9 \\
146,5 \pm 4,0\end{array}$ & PN-EN ISO $3405: 2019^{\wedge}$ \\
\hline Volatility index, VLI (VLI=10DVPE+7E70) & - & $746 \pm 36$ & $955 \pm 36$ & $830 \pm 36$ & $926 \pm 36$ & $952 \pm 36$ & $1018 \pm 36$ & $1074 \pm 36$ & PN-EN $228+$ A1:2017-06 \\
\hline
\end{tabular}




\section{Discussion of research results}

Figure 4 shows a comparison of the results obtained for the seven fuels tested according to the CEC F-113-KC procedure. The test result is the difference in the width of the electrical pulse controlling the opening time of the fuel injectors in a single fuel injection, measured before and after the test. Since the measured pulse is unstable and varies with very high frequency and relatively large amplitude over time, calculating the pulse width increment by simply comparing its magnitude at the beginning and end of the test could be subject to large error. Therefore, a methodology based on the use of a trend function is used instead because the values calculated from the trend are more representative than those that would be based on the end points of the measurement. In this way, the computed averages of the electrical pulse widths controlling the injection timing at the beginning and at the end of the test are obtained. The difference between the two represents the test result.

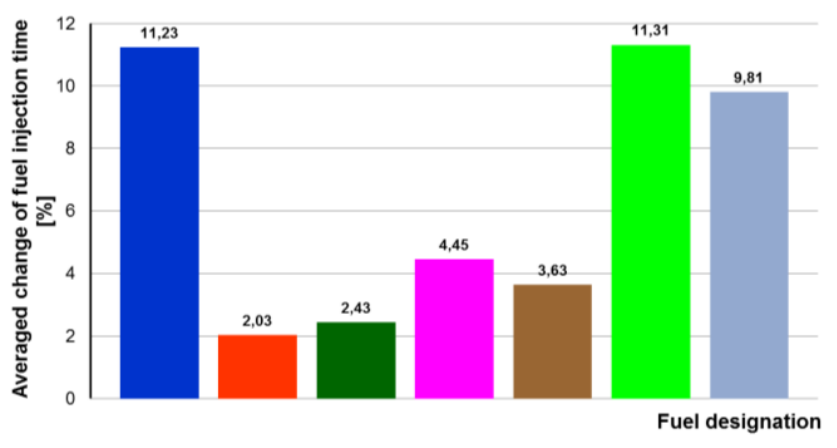

| BB95 - 1 | | BB95 - 2 | | BB95 - 3 || B898 - 1 | BB898 - 2 || BB95 - 3+10\%(V/N) E || BB98-1+10\%(V/V) E

Fig. 4. Comparison of the results of the DISI engine injector deposit tendency evaluations according to the CEC F-113-KC procedure

When proceeding to the evaluation of the results, it should be stressed that each engine construction, the strategy of combustion process organization in it and the injector construction have a great influence on the intensity of the injector coking phenomenon. Therefore, they also influence the final result of fuel assessment in the sense of progression of formation, as well as the size of injector deposits produced in a specific time. The evaluations described in the paper were carried out in accordance with the CEC F-113-KC procedure on VW EA111 BLG engine. It should also be pointed out that the fuel assessments carried out so far in many European laboratories according to the procedure mentioned above allowed, within the framework of the CEC TDG F-113 Working Group, to determine the repeatability of the results obtained using this method based on the Student's t-distribution.

It was calculated that in order to distinguish the two results with $95 \%$ confidence, an absolute difference between them of the magnitude of $3.0 \%$ change in the width of the electrical pulse controlling the opening time of the fuel injectors in a single fuel injection is required. However, given that this is in practice a large change in pulse size, it was determined that a smaller confidence interval (90\%) should be used in evaluating the results, for which an absolute difference between the results of the change in the width of the electrical pulse controlling the opening time of the fuel injectors in a single fuel injection of $1.8 \%$ is required. This allows sufficient differentiation and comparison of the results of the tested fuels.

Taking the above into account, the results of the evaluations of the seven fuels presented in Figure 4 can be divided into four groups. In each of these groups, fuel evaluations should be considered comparable from the statistical point of view. Thus, the same, in terms of propensity to form injector deposits, were evaluated fuels in groups: BB95-2 and BB95-3, the corresponding results of averaged fuel injection time changes are $2.03 \%$ and $2.43 \%$, BB98-1 and BB98-2 fuels, the corresponding results of averaged fuel injection time changes are $4.45 \%$ and $3.63 \%$, BB95-1 fuels, BB95-3 + 10\% (V/V) ethanol, the corresponding results of averaged fuel injection time changes are $11.23 \%$ and $11.31 \%$ and in the last group BB98-1 + 10\% (V/V) ethanol, with the result of averaged fuel injection time change of $9.81 \%$. When considering the fuel properties that may have influenced the above variation of results in the different groups, one should refer to Table 2 which contains a summary of the physicochemical properties of the gasoline samples prepared for engine testing. In the available literature, there is a lot of information and research descriptions, which indicate that such properties of unrefined fuel as: T90, vapour pressure, density, IBP, octane number and the content of olefins, aromatics and naphthenes as well as alcohol and sulphur have large or very large effect on the processes of formation of deposits on fuel injectors of IDID type engines. Unfortunately, in different studies the magnitude of the influences of these properties is evaluated differently and not only in terms of the intensity of the effect, but even in terms of the direction. As an example, we can use the $90 \%$ fuel evaporation temperature (T90), which, according to most publications, has a very large impact on the formation of deposits of injectors [4, 20-23], although there are also some research results, according to which it has practically no impact [24]. However, speaking about the high significance of T90 on deposit formation in some publications, one can find observations (conclusions) that: high level of T90 can increase fouling of injectors due to lower volatility of fuel allowing formation of deposits in outlet channels and around injector orifices (slower volatilization leading to longer time of fuel staying on hot surfaces of injector tip and consequently faster oxidation and eventually carbonization) [20-22, 25]. In other publications it is argued that: low T90 is responsible for injector fouling due to the higher volatility of the fuel (shorter time the fuel remains on the injector surface, which limits the intensity of cleaning, and furthermore, higher volatility causes higher molecular weight components to be oxidized and carbonized on the hot injector tip surface) [14, 23]. A great difficulty in the interpretation of the obtained results is usually the significant variation of at least several properties of the evaluated fuels. The obtained test result is a resultant of interactions of various fuel properties, some of which may interact with each other in ways that are very difficult to determine and which may have various impacts on injector deposit formation. Comparing the results of injector fouling for fuels BB95-1, BB95-2 and BB95-3, i.e. petrols of LOB $=95$, we see that a significantly different result was ob- 
tained for BB95-1 (11.23\%). Analysing properties of these petrols (Table 2), it may be assumed that the reason of such a high result in case of BB95-1 petrol may be high sulphur content (such hypothesis is consistent with research results presented in $[15,24]$ ), significantly higher T90 value in comparison to the two remaining petrols (it coincides with conclusions presented in [20-22, 25]), higher content of aromatic hydrocarbons (it coincides with conclusions presented in [15, 21], and higher density (such conclusions were also drawn in work [24]). The differences in the properties of BB95-2 and BB95-3 fuels contained in Table 2 were not found to be large enough to significantly affect the results of their evaluations $(2.03 \%$ and $2.43 \%$, respective$1 y)$, and therefore to distinguish between these fuels at the assumed confidence interval (90\%). The comparison of two gasolines with $\mathrm{LOB}=98$, i.e. gasoline BB98-1 and BB982 , indicates gasoline BB98-1 as having a higher tendency to form injector deposits. The reason for this can be sought in higher sulfur content (hypothesis consistent with [23, 26]), higher vapor pressure (similar observations in [24]), higher aromatic hydrocarbon content (consistent with observations in $[15,21]$ ), and higher density (similar observations in [24]). A property that could counteract the greater variation in results between these fuels could be the lower IBP value for BB98-1 gasoline, which according to e.g. [24] contributes to the reduction of injector deposits formed. However, the most interesting and surprising results were obtained when $10 \%(\mathrm{~V} / \mathrm{V})$ ethanol was added to BB95-3 and BB98-1 gasolines. Investigations of the samples prepared in this way, labeled BB95-3 + 10\% (V/V) ethanol and BB98-1 + $10 \%(\mathrm{~V} / \mathrm{V})$ ethanol, showed, in both cases, a very significant increase in the propensity to foul the injectors $(11.31 \%$ and $9.81 \%$, respectively) which is a result inconsistent with those described in $[15,21,27]$, but coincident with the results reported in [28]. The higher result of injector fouling by BB95-3 + 10\% (V/V) ethanol fuel compared to BB98-1 $+10 \%(\mathrm{~V} / \mathrm{V})$ ethanol fuel may have been influenced by higher olefinic hydrocarbon content (similar observations reported in [22, 24, 29-31], higher IBP value (similar observations reported in [24]), and possibly higher T90 value (this would be consistent with observations in [20-25]).

It is also interesting to compare the course of sediment formation for all the tested fuel samples during 48 hours of the test - Fig. 5 .

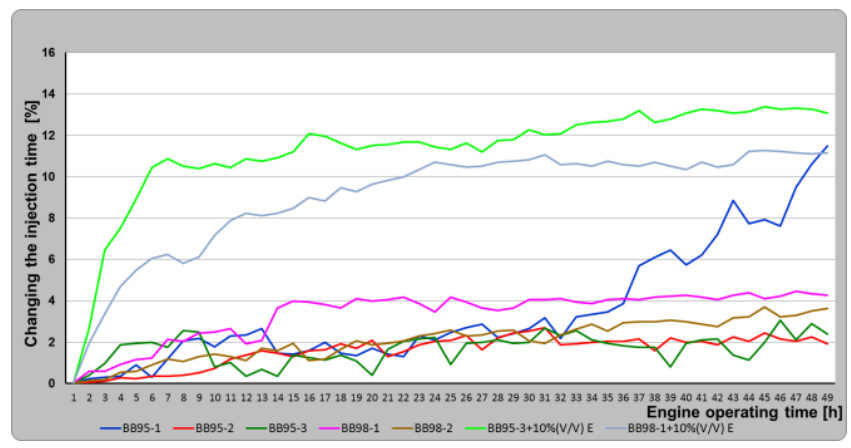

Fig. 5. Summary of fuel injection time variation results for the tested gasoline samples
All the runs presented in Fig. 5 are characterized by gradual but unstable increase in time. The results show significant fluctuations of fuel injection time changes during the test, particularly high for BB95-3, BB95-2 and BB95-1 fuels. Such a phenomenon is known e.g. in the case of deposits formation on engine intake valves [32, 33]. In order to determine the trends of changes in the processes of deposits formed in injectors by the tested petrols during the tests, the lines of their trends were presented in Fig. 6.

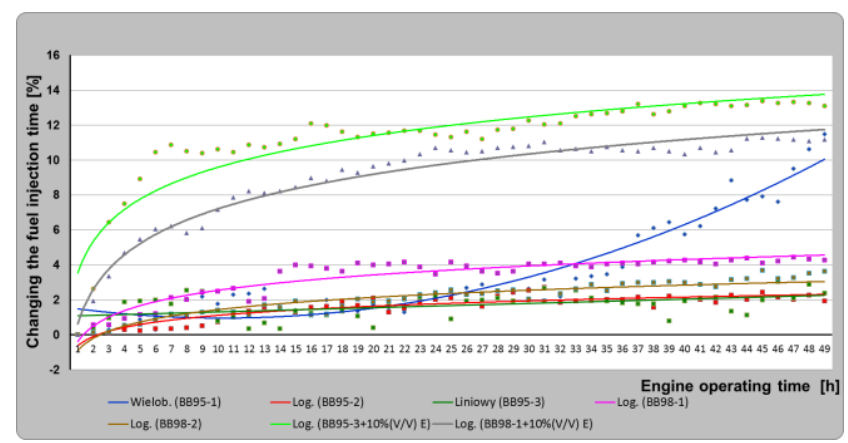

Fig. 6. Summary of trend lines of fuel injection time changes for the tested gasoline samples

As can be seen - Fig. 6, most of the fuel injection time changes for the tested gasoline samples have a logarithmic course. This is the case for BB95-2, BB98-1, BB98-2, $\mathrm{BB} 953+10 \%(\mathrm{~V} / \mathrm{V})$ ethanol and BB98-1 + 10\% (V/V) ethanol. Only for fuel BB95-1 the waveform is polynomial and for fuel BB95-3 the waveform is linear. The differences in trends in the formation of the size of deposits in the injectors exposed to the influence of the fuels studied result from the intensity of the processes of formation of the deposits precursors, the force of their adhesion to the surface on which they form and the simultaneous processes of selfcleaning of the injectors. Logarithmic run indicates more intensive process of sediment precursors formation at the beginning of injector contamination process, stronger sediment adhesion to the surface and/or lower intensity of sediment removal (washout) from the surface (e.g. due to higher T90). On the other hand, polynomial trend of deposits formation indicates slower process of deposits precursors formation at the beginning of injectors fouling and their weak adhesion to the surface, which can be related to parallel, intensive process of their removal (washing away) due to, for instance, low T90. In the case of linear course of action, the processes of sediment formation and sediment removal take place with constant intensity in defined proportion, with predominance of injector fouling processes. After the sediment precursors are formed and stabilized on the surface of the injectors, further injector fouling is a resultant of the processes of sediment growth and its removal.

The last evaluation of the injector deposits formed by the fuels subjected to the tests was their visual assessment, which is contained in Table 3 . It is limited to the description of deposits formed on the front surface of the injector nozzles, the area of convexity of this surface, on which six fuel outlet holes are located, and deposits in the outer part of fuel channels. The evaluation was based on a description of deposits of one injector, representative for each test. It 
shows that the largest deposits, at the same time in the most critical areas (on the walls of the external parts of the fuel injector tubules), were formed in the BB95-1, BB95-3+ $10 \%(\mathrm{~V} / \mathrm{V})$ ethanol and BB98-1 + 10\% (V/V) ethanol fuel tests. Such deposits cause both a reduction in the rate of fuel flow out of the injectors and a deterioration in the quality of fuel jet atomization.

Table 3. Deposits on representative injectors for each of the fuel tests performed

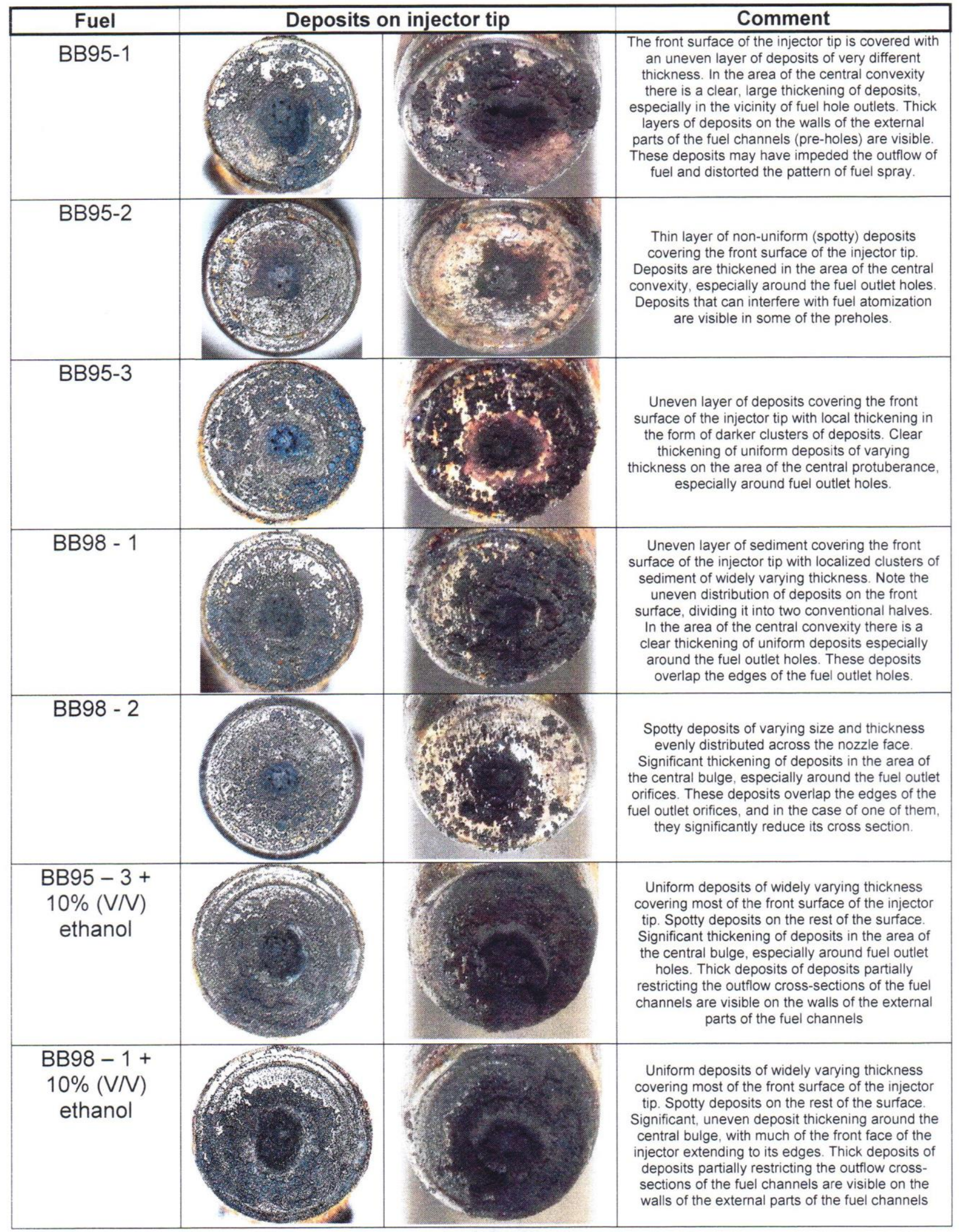




\section{Conclusion}

1) The results of the project proved that the physicochemical properties and composition of gasoline have a great influence on both the initiation, rate of formation and size of deposits formed on injectors of SI type DISI engines.

2) The rapid changes in the pulse width of the fuel injection time, observed during the tests, indicate the simultaneous processes of fuel injector deposit formation and cleaning. The final result of the injector contamination level is a resultant of these processes.

3) The results of the study showed that increased sulfur content in gasoline and increased proportion of aromatic hydrocarbons and high temperature T90 are the main factors promoting and intensifying the phenomenon of fuel injector deposit formation.

4) In the case of the fuel samples tested, an increased tendency to form injector deposits was observed in gasolines containing ethanol.

5) When gasolines with ROM $95+10 \%$ ethanol and ROM $98+10 \%$ ethanol were compared, a higher propensity for injector deposits was observed for the former. Analyzing the composition and physicochemical properties of these gasolines, higher olefinic hydrocarbon content and higher IBP and T90 values were indicated as the reason for the formation of more deposits in the case of gasoline with ROM $95+10 \%$ ethanol.
6) Gasoline ethanol admixture was observed to cause a rapid increase in deposit size in the first 8-10 h of the test, followed by a slow increase in the remainder of the test.

7) The extent of injector fouling is determined by the combined effect of all factors both supporting and limiting the deposit formation process. Moreover, some of the factors may interact with each other in ways difficult to determine.

8) Differences in the trends of deposit formation on the injectors exposed to the influence of the fuels studied result from the intensity of the processes of formation of deposit precursors and the force of their adhesion to the surface on which they form and then the intensity of deposit growth and simultaneous processes of injectors self-cleaning.

9) The results of tests carried out in the project according to the research procedure CEC F-113-KC indicate T90, aromatic and olefinic hydrocarbons, sulphur, ethanol, DVPE, IBP and fuel density as the most important factors causing the increase in the tendency for deposits to form on the injectors of SI engines with direct fuel injection.

\section{Acknowledgements}

This work is supported by the Ministry of Science and Higher Education Republic of Poland. Grant number INiG$\mathrm{PIB} / 0023 / \mathrm{TE} / 20$.

\section{Nomenclature}

$\begin{array}{llll}\text { SI } & \text { Spark Ignition } & \text { DCA } & \begin{array}{l}\text { Deposit Control Additives } \\ \text { Gasoline 90\% Distillation Temperature }\end{array} \\ \text { DISI } & \text { Direct Injection Spark Ignition } & \text { T90 } & \begin{array}{l}\text { The Coordinating European Council for the } \\ \text { WWFCh }\end{array} \\ \text { Worldwide Fuel Charter } & \text { CEC } & & \begin{array}{l}\text { Development of Performance Tests for } \\ \text { Transportation Fuels, Lubricants and Other }\end{array} \\ \text { PFI } & \text { Port Fuel Injection } & & \text { Fluids } \\ \text { GDI } & \text { Gasoline Direct Injection } & & \text { Initial Boiling Point } \\ \text { STFT } & \text { Short Term Fuel Trim } & \text { IBP } & \\ \text { LTFT } & \text { Long Term Fuel Trim } & \end{array}$

\section{Bibliography}

[1] Worldwide Fuel Chapter, September 2013

[2] ZHAO, F., LAI, M-C., HARRINGTON, D.L. Automotive spark-ignited direct-injection gasoline engines. Progress in Energy and Combustion Science. 1999, 25, 437-562.

[3] LINDGREN, R., SKOGSBERG, M., SANDQUIST, H. et al. The influence of injector deposits on mixture formation in a DISC SI engine. JSAE Technical Paper 2003-01-1771. 2003. https://doi.org/10.4271/2003-01-1771

[4] ARTERS, D., BARDASZ, E., SCHIFLER, E. et al. A comparison of gasoline direct injection. Part I - fuel system deposits and vehicle performance. SAE Technical Paper 199901-1498. 1999. https://doi.org/10.4271/1999-01-1498

[5] DuMONT, R.J., EVANS, J.A., FEIST, D.P. et. al. Test and control of fuel injector deposits in direct injected spark ignition vehicles. SAE Technical Paper 2009-01-2641. 2009. https://doi.org/10.4271/2009-01-2641

[6] CARLISLE, H.W., FREW, R.W., MILLS, JR. et. al. The effect of fuel composition and additive content on injector deposits and performance of an air-assisted direct injection spark ignition (DISI) research engine. SAE Technical Paper 2001-01-2030. 2001. https://doi.org/10.4271/2001-01-2030
[7] NOMA, K., IWAMOTO, Y., MURAKAMI, N. et. al. optimized gasoline direct injection engine for the European market. SAE Technical Paper 980150. 1998. https://doi.org/10.4271/980150

[8] SANDQUIST, H., DENBRATT, I., OWRANG, F. et. al. Influence of fuel parameters on deposit formation and emissions in a direct injection stratified charge SI engine. SAE Technical Paper 2001-01-2028. 2001. https://doi.org/10.4271/2001-01-2028

[9] WHITEHEAD, M.A., BUCKINGHAM, J.P., BRUNNER, J.K. The port fuel injector deposit test - a statistical review. SAE Technical Paper 982713. 1998. https://doi.org/10.4271/982713

[10] HIROYUKI, Y., OSAMU, A., HIDETOSHI, E. et. al. Mixture formation of direct gasoline injection engine: incylinder gas sampling using fast flame ionization detector. JSAE Review. 1999, 20(1), 23-29. https://doi.org/10.1016/S0389-4304(98)00042-3

[11] JOEDICKE, A., KRUEGER-VENUS, J., BOHR, P. et. al. Understanding the Effect of DISI injector deposits on vehicle performance. SAE Technical Paper 2012-01-0391. 2012. https://doi.org/10.4271/2012-01-0391 
[12] BARKER, J., REID, J., MULQUEEN, S. et. al. The investigation of the structure and origins of gasoline direct injection (GDI) deposits. SAE Technical Paper 2019-01-2356. 2019. https://doi.org/10.4271/2019-01-2356

[13] CHINA, P., RIVERE, J.P. Development of a direct injection spark ignition engine test for injector fouling. JSAE Technical Paper 2003-01-2006. 2003. https://doi.org/10.4271/2003-01-2006

[14] VON BACHO, P., SOFIANEK, J., GALANTE-FOX, J. et. al. Engine test for accelerated fuel deposit formation on injectors used in gasoline direct injection engines. SAE Technical Paper 2009-01-1495. 2009. https://doi.org/10.4271/2009-01-1495.

[15] ASHIDA, T., TAKEI, Y., HOSI, H. Effects of fuel properties on SIDI fuel injector deposit. SAE Technical Paper 2001-01-3694. 2001. https://doi.org/10.4271/2001-01-3694

[16] ARTERS, D.C., MACDUFF, M.J. The effect on vehicle performance of injector deposits in a direct injection gasoline engine. SAE Technical Paper 2000-01-2021. 2000. https://doi.org/10.4271/2000-01-2021

[17] ARADI, A.A., HOTCHKISS, A., IMOEHL, B. et. al. The effect of fuel composition, engine operating parameters and additives on injector deposits in a high-pressure direct injection gasoline (DIG) research engine. Aachen Colloquium Automobile and Engine Technology. 2000, 187-211.

[18] BENETT, J. Gasoline direct injection engines the effects of deposit control and removal. 2018. Afton Chemical. https://www.umtf.de/pdf/vortrag_2017/04.04_04_Dr.\%20Be nnett\%20-\%20Gasoline\%20direct\%20injection\%20engines $\% 20$ and $\% 20$ the $\% 20$ effects $\% 20$ of $\% 20$ deposit $\% 20$ control $\% 2$ 0and\%20removal.pdf

[19] TDG - F-113 CEC New Test Development - Proposal for a New Engine Fuels Test Procedure. CEC Materials. https://www.cectests.org/public/info_/g003/Appendix\%201_ CEC\%20New\%20Test\%20Development\%20\%20Terms\%20of\%20Reference\%20-TDG-F-113.pdf

[20] HONGMING, X., CHONGMING, W., XIAO M. Fuel injector deposits in direct-injection spark-ignition engines. Progress in Energy and Combustion Science. 2015, 1-69. https://doi.org/10.1016/j.pecs.2015.02.002

[21] ARONDEL, M., CHINA, P., GUEIT, J. Evaluating injector fouling in direct injection spark ignition engines - a new engine test procedure to evaluate the deposit control performance of base fuels and additivated fuels. TAE Esslingen Fuels Colloquium 2015.

[22] ARADI, A.A., EVANS, J., MILLER, K. et. al. Direct injection gasoline (DIG) injector deposit control with additives. SAE Technical Paper 2003-01-2024. 2003.

https://doi.org/10.4271/2003-01-2024
[23] FERNANDES, H., BRAGA, LC., MARTINS, A. et. al. Fuel sulfate content influence in the formation of inorganics components deposits in the engine injectors with technologies of gasoline direct injection. SAE Technical Paper 201236-0314. 2012. https://doi.org/10.4271/2012-36-0314

[24] PILBEAM, J., WEISSENBERGER, D. Characterisation of gasoline fuels in a DISI engine. Afton Chemical. Bracknell, UK. SGS S.A. Vienna, Austria.

https://issuu.com/afton_chemical/docs/aftonchemical_chara cterization_of_g

[25] BADAWY, T., ATTAR, A.M., HUTCHINS, P. et. al. Investigation of injector coking effects on spray characteristic and engine performance in gasoline direct injection engines. $A p$ plied Energy. 2018, 220. 375-394.

https://doi.org/10.1016/j.apenergy.2018.03.133

[26] $\mathrm{K}-\mathrm{i} \mathrm{S}$. The efforts to the fuel quality for the environment load reduction - compatible of the gasoline quality to the new vehicle technology. Nippon Mitsubishi Oil Vehicle Symposium. 2000.

[27] TANIGUCHI, S., YOSHIDA, K., TSUKASAKI, Y. Feasibility study of ethanol applications to a direct injection gasoline engine journal. SAE Technical Paper 2007-01-2037. 2007. https://doi.org/10.4271/2007-01-2037

[28] RUSSELl, M., CUMMINGS, J., CUSHING, T. et. al. Cellulosic ethanol fuel quality evaluation and its effects on PFI intake valve deposits and GDI fuel injector plugging performance. SAE Technical Paper 2013-01-0885. 2013. https://doi.org/10.4271/2013-01-0885

[29] ARADI, A.A., IMOEHL, B., AVERY, N.L. et. al. The effect of fuel composition and engine operating parameters on injector deposits in a high-pressure direct injection gasoline (DIG) research engine. SAE Technical Paper 1999-013690. 1999. https://doi.org/10.4271/1999-01-3690

[30] UEHARA, T., TAKEI, Y., HOSHI, H. et. al. Study on combustion chamber deposit formation mechanism influence of fuel components and gasoline detergents. SAE Technical Paper 971722. 1997. https://doi.org/10.4271/971722

[31] ARADI, A.A., COLUCCI, W.J., SCULL, H.M. et. al. A study of fuel additives for direct injection gasoline (DIG) injector deposit control. SAE Technical Paper 2000-01-2020. 2000. https://doi.org/10.4271/2000-01-2020

[32] STĘPIEN, Z. Deposit in spark ignition engines - formation and threats. Combustion Engines. 2015, 160(1), 36-48.

[33] STĘPIEŃ, Z. Types of internal diesel injector deposits and counteracting their formation. Combustion Engines. 2015, 163(4), 79-91. 